\title{
Article \\ A Comparative Assessment of Mid-Water Trawl and Deep Vision for Investigating Fishery Resources in the Coastal Waters off Jeju Island, Korea
}

\author{
Yong-Deuk Lee ${ }^{1}$, Hyungbeen Lee ${ }^{1, *}$, Euna Yoon ${ }^{1}{ }^{1}$, Cheol Park $^{1}$, Eirik Svoren Osborg ${ }^{2}$ and Kristoffer Løvall ${ }^{2}$ \\ 1 Fisheries Resources Research Center, National Institute of Fisheries Science (NIFS), Tongyeong 53064, Korea; \\ forest87@paran.com (Y.-D.L.); euna85@korea.kr (E.Y.); zzong10047@gmail.com (C.P.) \\ 2 Scantrol Deep Vision AS, 5035 Bergen, Norway; Eirik@deepvision.no (E.S.O.); Kristoffer@deepvision.no (K.L.) \\ * Correspondence: hblee00@korea.kr; Tel.: +82-55-650-2250
}

check for

updates

Citation: Lee, Y.-D.; Lee, H.; Yoon, E.; Park, C.; Osborg, E.S.; Løvall, K. A Comparative Assessment of Mid-Water Trawl and Deep Vision for Investigating Fishery Resources in the Coastal Waters off Jeju Island, Korea. Appl. Sci. 2022, 12, 1835. https://doi.org/10.3390/ app12041835

Academic Editor: Pierpaolo Consoli

Received: 15 December 2021

Accepted: 8 February 2022

Published: 10 February 2022

Publisher's Note: MDPI stays neutral with regard to jurisdictional claims in published maps and institutional affiliations.

Copyright: (c) 2022 by the authors. Licensee MDPI, Basel, Switzerland. This article is an open access article distributed under the terms and conditions of the Creative Commons Attribution (CC BY) license (https:// creativecommons.org/licenses/by/ $4.0 /)$.

\begin{abstract}
Acoustic-trawl surveys use trawl sampling to identify aquatic species. The Deep Vision stereo camera system collects images of fish passing through trawl extensions. We conducted a survey using Deep Vision with a mid-water trawl to identify and measure the lengths of domestic fish species in October 2020 and July 2021 in coastal waters off Jeju Island, Korea. We identified $86.4 \%$ of 22 species captured from images and estimated the lengths of $40 \%$ of the identified fish. A comparison of species numbers identified by mid-water trawl and Deep Vision revealed that, with the exception of three species with fewer than five individuals, identification was consistent. Our results indicate that the combined use of Deep Vision and mid-water trawl can be an eco-friendly and effective approach of examining the spatial distribution and size of fish species.
\end{abstract}

Keywords: Deep Vision; midwater trawl; Jeju Island; fisheries resources; eco-friendly

\section{Introduction}

Direct resource surveys for fisheries research include trawl, ichthyoplankton, underwater acoustic, and sighting surveys, along with scientific evaluation. Resource quantity estimates of fishery resources based on these methods are of particular importance from the perspective of resource management of major commercial species [1,2]. Trawl surveys quantify fishery catches primarily by using scientific research vessels and have been continuously conducted since 1930 to identify and evaluate the spatiotemporal distribution and resource quantity of major commercial fish species worldwide [3,4]. In addition, given that the acoustic survey method using a scientific echosounder can estimate the spatiotemporal distribution and existing amounts of fishery organisms over large surveys area in a short period of time, research on major pelagic fish species such as North Pacific pollock and Atlantic mackerel has been widely conducted since the 1980s [5-7]. Acoustic surveys enhance the accuracy of acoustic estimations by identifying and determining the length distribution of major pelagic fish species alongside trawl surveys [8]. Mid-water trawl surveys, which catch pelagic fish detected by scientific echosounders, have a significant advantage in species identification when a single species is caught. However, they are limited with respect to temporal and spatial analyses of biological resources, such as vertical distribution of specific fish species. Furthermore, such surveys based on body length analyses are limited if catches accumulate in the codend of trawl nets, in which multiple species are mixed and distributed according to the fluctuation of catch depth [9]. In addition, surveys using fishing gear can directly or indirectly affect the marine environment [10]. To minimize damage to biological resources, eco-friendly studies are increasingly being conducted to identify ecological characteristics, such as the depth distribution of organisms, by installing underwater cameras on trawl gear or using autonomous underwater vehicles (AUVs) or underwater drones [11-14]. 
Unlike conventional research methods that involve the direct collection of target species, the recently developed and commercialized Deep Vision (Scantrol Deep Vision AS, Bergen, Norway) uses a stereo camera to identify and measure fish species passing through the device after being caught by mid-water trawls [15]. In addition, the system can determine the spatiotemporal distribution of fish species caught along the trawl path and measure the length to an accuracy of within less than 5\% [15]. Therefore, Deep Vision is an eco-friendly research technology that can be used to facilitate species identification, distribution depth, and length measurements without catching organisms, as the codend can be opened during trawl surveys.

Previous comparative studies using Deep Vision have verified the results of species identification and length measurements for major migratory pelagic fish such as Arctic cod (Arctogadus glacialis), haddock (Melanogrammus aeglefinus), and Atlantic mackerel (Scomber scombrus), using an acoustic survey and a mid-water trawl with Deep Vision installed [16-18]. An earlier study described the accuracy of the length measurement of fish imaged using Deep Vision [15]. Although Deep Vision has been introduced for the third time globally and for the first time in Korea, major fish species in Korean waters have yet to be sufficiently studied. In addition, the development of technologies to facilitate the sustainable management of domestic fisheries and conservation of marine ecosystems is required. Consequently, it is necessary to devise eco-friendly survey methods with minimal negative impacts on fisheries resources. Accordingly, it is necessary to verify the results of species identification and the length measurement based on mid-water trawl surveys using Deep Vision for the major domestic pelagic fish, including chub mackerel (Scomber japonicus), Japanese jack mackerel (Trachurus japonicus), and largehead hairtail (Trichiurus lepturus).

In the present study, using a mid-water trawl survey in conjunction with Deep Vision, we undertook comparative verifications of the species, populations, and sizes of major pelagic fish distributed in the coastal waters off Jeju Island, Korea. The results of the present study present a potential eco-friendly fishery resource survey method that can secure ecological information without catching target species.

\section{Materials and Methods}

\subsection{Measurement Apparatus}

In this study, we conducted a mid-water trawl survey with Deep Vision installed as part of a fishery acoustic survey using a scientific echosounder for major pelagic fish species in the coastal waters off Jeju Island, Korea, in October 2020 and July 2021, onboard $\mathrm{R} / \mathrm{V}$ Tamgu23, the fisheries scientific research vessel of the National Institute of Fisheries Science (Figure 1). The acoustic surveys of pelagic fish were carried out along a set acoustic transects in the surveyed area, and a fishery survey using mid-water trawls was conducted in parallel, to identify the schools of pelagic fish.

The acoustic data for volume backscattering strength (SV, $\mathrm{dB}$ re $1 \mathrm{~m}^{-1}$ ) were collected using a Simrad EK80 scientific echosounder using 18, 38, 70, 120, 200, and 333-kHz splitbeam transducers, which were mounted on the bottom of the ship, the hull depth of which was approximately $5.4 \mathrm{~m}$. Prior to conducting acoustic surveys, the acoustic system was calibrated using a calibration sphere. A pulse length of $1024 \mathrm{~ms}$ and ping rate of $2 \mathrm{~s}$ were employed at all frequencies, with a constant ship speed of 9 knots between trawl surveys. 


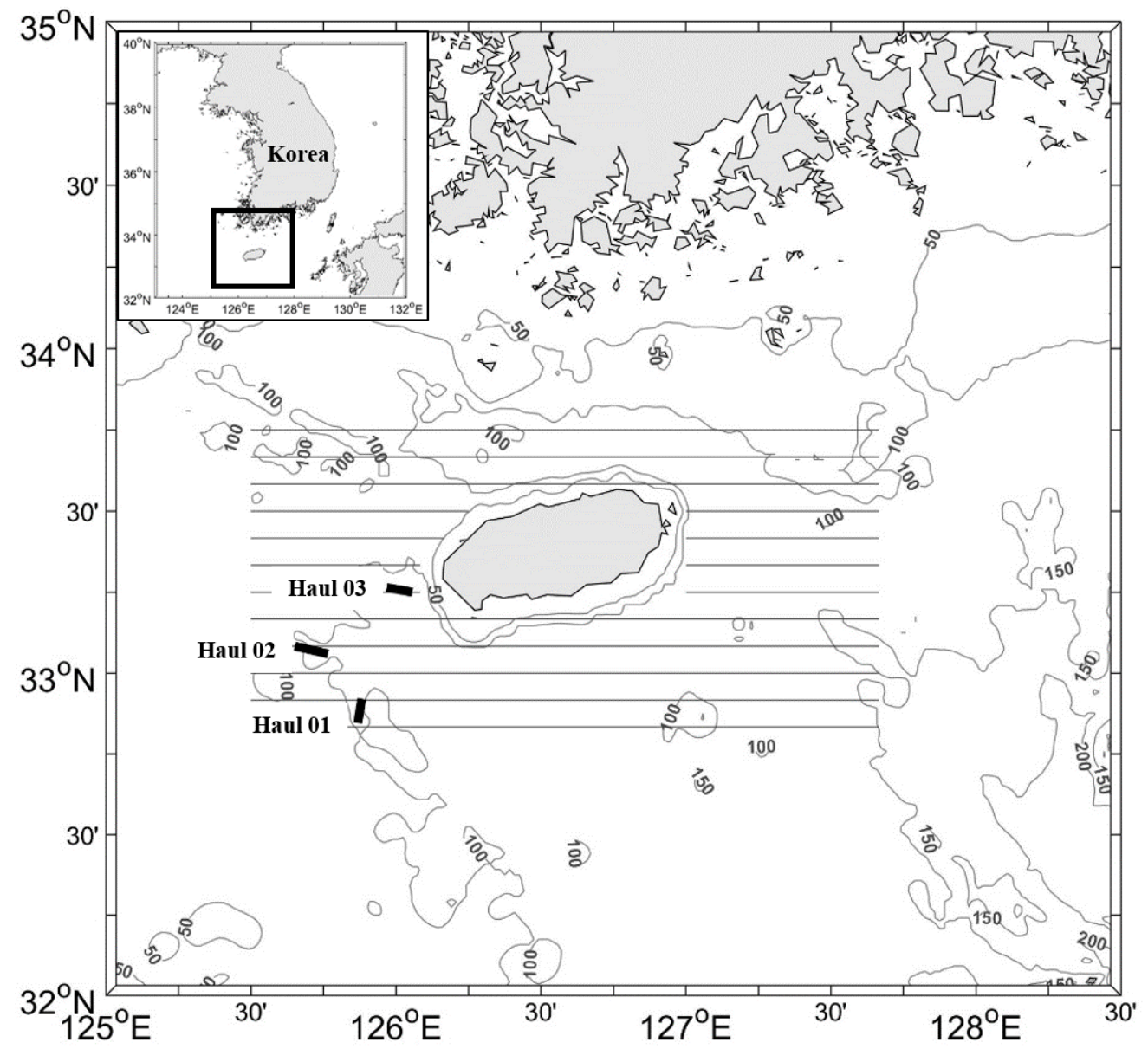

Figure 1. Map showing the transect lines and trawling station in Western sea of Jeju Island. The black bold lines indicate the trawling locations; thin gray lines indicate the transect line for the acoustic survey.

For the purposes of the fishery survey, we conducted three $30 \mathrm{~min}$ mid-water trawls at a ship speed of approximately 4.7 knots using trawl gear consisting of a hand rope $(97 \mathrm{~m})$, net pendant $(97 \mathrm{~m})$, and codend mesh size $(30 \mathrm{~mm})$ (Table 1). During towing, fish school signals detected by the scientific echosounder were examined in real time and the towing depth of the mid-water trawl was altered to catch the fish according to the distribution depth of the fish schools (Figure 2). The fish thus captured were identified at species level, and the population, wet weight (to within $0.1 \mathrm{~kg}$ ), and total length (to within $0.1 \mathrm{~cm}$ ) were measured. In the case of a large catch numbers, the total catch was divided, and we obtained measurements from up to 100 individuals. After the fishery survey, a marine environment survey was conducted using CTD (conductivity-temperature-depth; Sea-Bird, SBE 911plus).

Table 1. Details of the acoustic and mid-water trawl survey.

\begin{tabular}{|c|c|c|c|c|c|c|c|}
\hline \multirow[b]{2}{*}{ Trawl } & \multirow{2}{*}{$\begin{array}{c}\text { Date } \\
\text { (YYYY. MM. DD) }\end{array}$} & \multicolumn{2}{|c|}{ Location } & \multirow{2}{*}{$\begin{array}{c}\text { Mean } \\
\text { Depth } \\
(\mathrm{m})\end{array}$} & \multirow[b]{2}{*}{$\begin{array}{l}\text { Speed } \\
\text { (Knot) }\end{array}$} & \multirow[b]{2}{*}{$\begin{array}{l}\text { Temperature }\left({ }^{\circ} \mathrm{C}\right) \\
\text { (Surface/Bottom) }\end{array}$} & \multirow[b]{2}{*}{$\begin{array}{c}\text { Salinity (psu) } \\
\text { (Surface/Bottom) }\end{array}$} \\
\hline & & $\begin{array}{c}\text { Start } \\
\text { (Latitude/Longitude) }\end{array}$ & $\begin{array}{c}\text { End } \\
\text { (Latitude/Longitude) }\end{array}$ & & & & \\
\hline Haul 01 & 2020. 10. 19 . & $32^{\circ} 53.8^{\prime} / 125^{\circ} 52.8^{\prime}$ & $32^{\circ} 51.5^{\prime} / 125^{\circ} 52.4^{\prime}$ & 104.2 & 4.4 & $22.08 / 16.92$ & $32.74 / 34.40$ \\
\hline Haul 02 & 2020. 10. 21. & $33^{\circ} 04.8^{\prime} / 125^{\circ} 41.0^{\prime}$ & $33^{\circ} 04.5^{\prime} / 125^{\circ} 44.4^{\prime}$ & 107.6 & 5.1 & $22.87 / 16.74$ & $33.72 / 34.55$ \\
\hline Haul 03 & 2021. 07. 17. & $33^{\circ} 15.0^{\prime} / 126^{\circ} 02.0^{\prime}$ & $33^{\circ} 15.0^{\prime} / 125^{\circ} 58.6^{\prime}$ & 110.3 & 4.6 & $28.30 / 14.93$ & $27.38 / 34.05$ \\
\hline
\end{tabular}

Deep Vision consists of a main body installed at the front of the codend of a midwater trawl and a trawl deck network device. The main body consists of a stereo camera 
(1.4 million pixels), strobe light, and battery encased in an underwater housing, such that all fish passing through the trawl net are photographed using synchronized stereo still images (Figure 3). As the strobe in Deep Vision comprises two light-emitting diodes with a brightness of $38,400 \mathrm{~lm}$, there is no difference in image brightness depending on water depth. The battery can be used for up to $8 \mathrm{~h}$, and a built-in depth sensor simultaneously collects data on the water level at which fish are caught. In addition, images of all fish species passing through the Deep Vision body along the trawl survey route were taken continuously in five stereo frames per second.

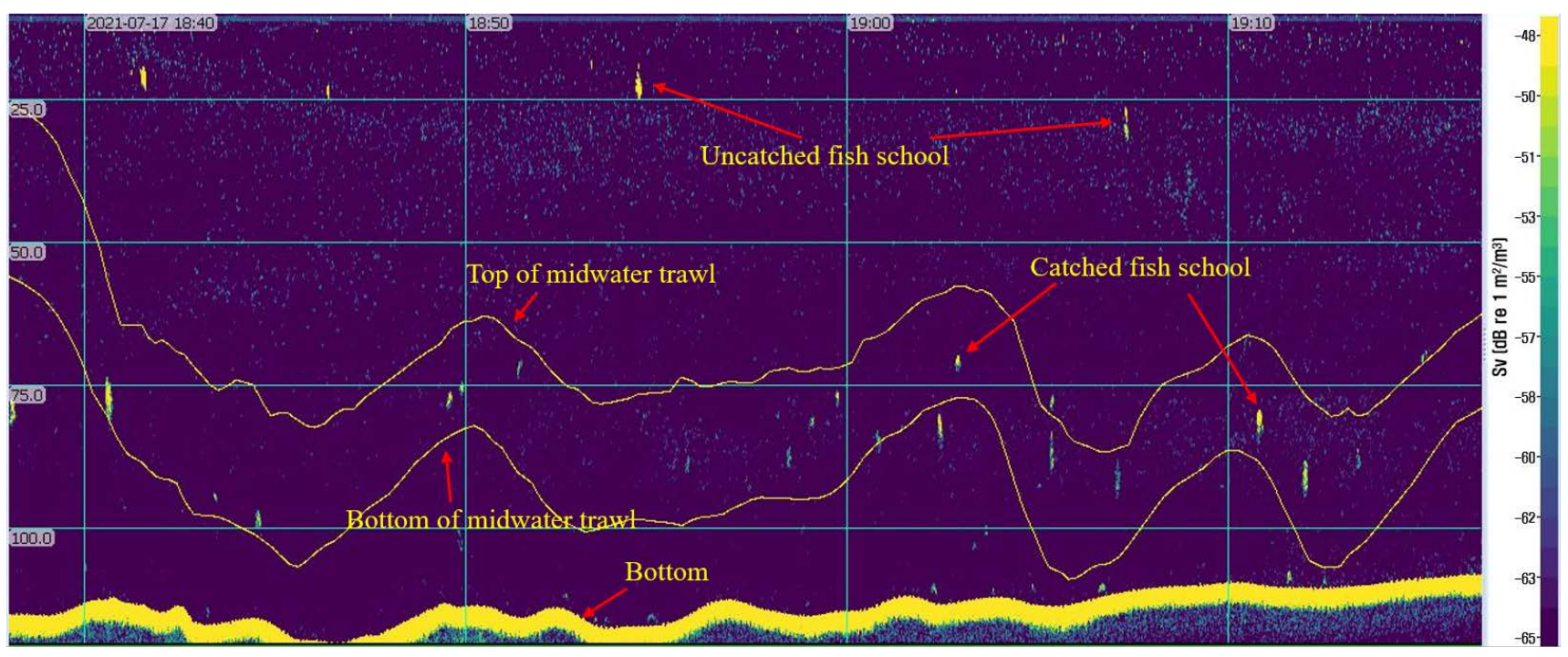

Figure 2. Echogram at $38 \mathrm{kHz}$ recorded during haul03 of mid-water trawl deployment. The yellow lines represent data obtained using the water depth sensor attached to the top and bottom of the net.

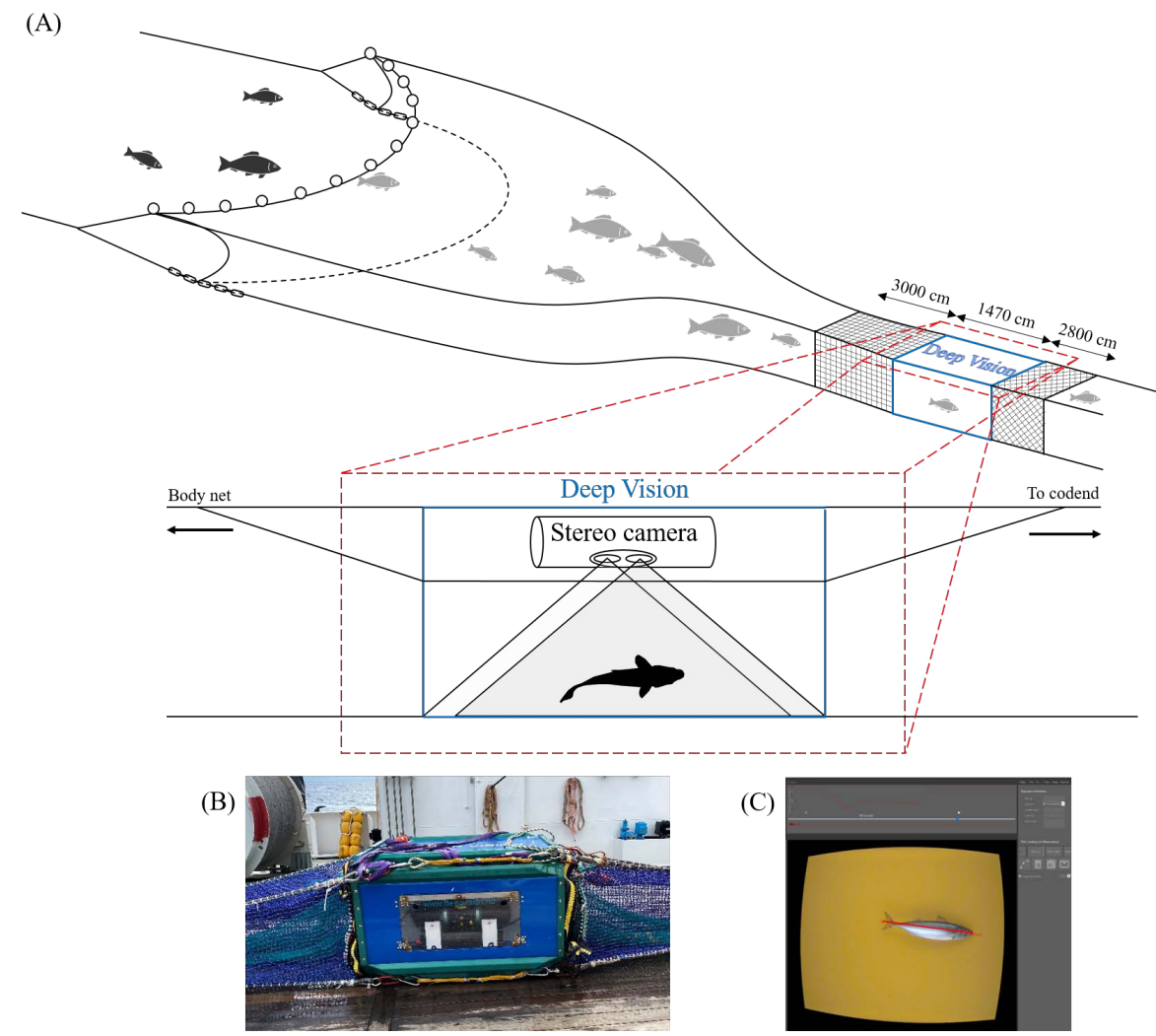

Figure 3. A schematic representation of the Deep Vision frame and trawl section (A); A photograph of Deep Vision (B); the Deep Vision length measurement system (C). 


\subsection{Data Processing}

We used specialized software (Deep Vision Analysis 3.3RC9; Scantrol AS, Bergen, Norway) to analyze the images obtained using Deep Vision. During analyses, fish were identified based on image filtering, and their movements were tracked to enumerate the fish species moving toward the codend from the trawl entrance. However, fish exiting toward the trawl entrance were excluded from population counts (Figure 4). Total length measurements of the fish were performed using the manual measurement function within the program. For details on the camera system and measurement accuracy, please refer to previous publications $[15,17]$. In addition, when photographing fish schools, fish were excluded from length measurements if the image overlapped with other fish specimens, or if the entire fish body was not shown in the image. The difference between the actual length of fish species caught by the trawl and the length measured through Deep Vision images was verified with a Welch two-sample t-test using $\mathrm{R}$ version 4.1.2 (The R Foundation for Statistical Computing, Vienna, Austria).

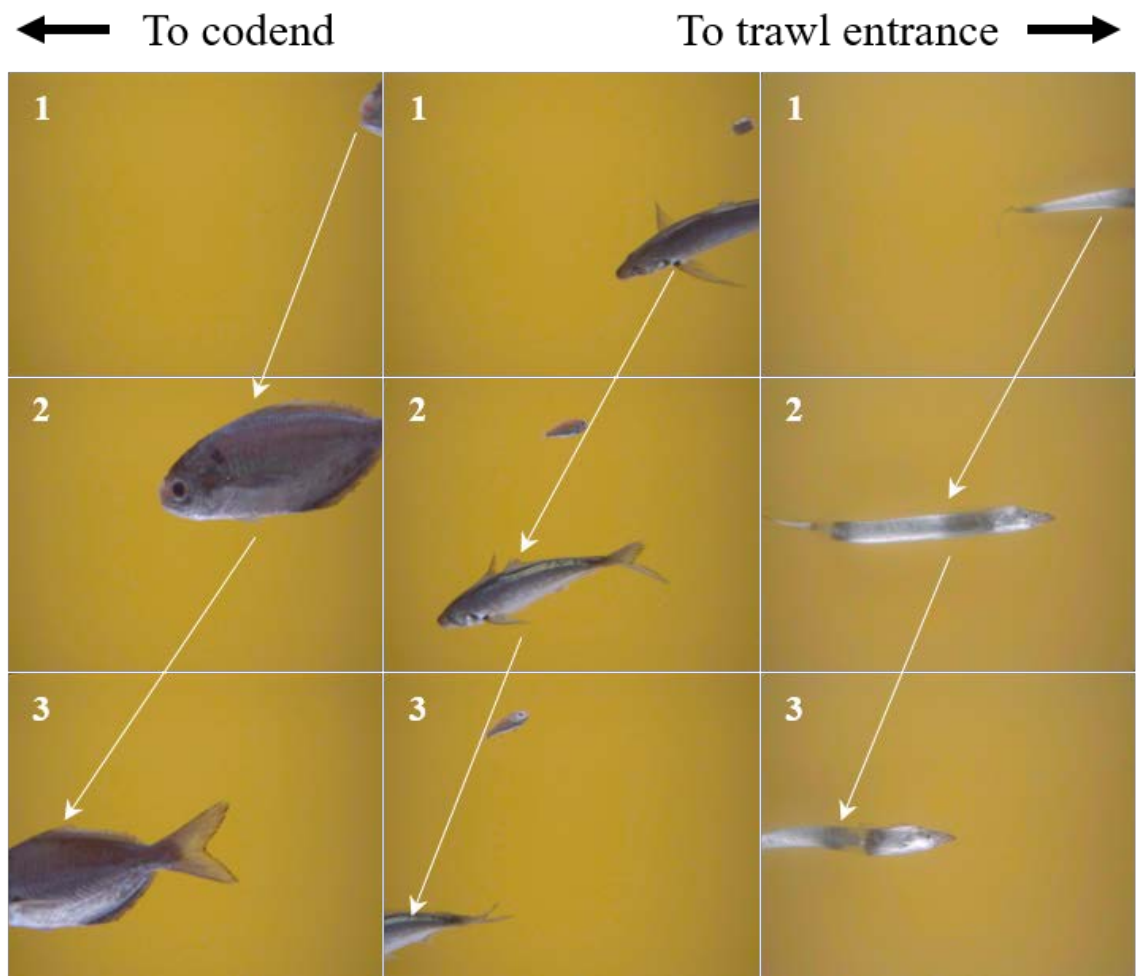

Figure 4. Example of tracking fish through sequential images 1 to 3 . The white arrow indicates the movement of each species.

\section{Results}

The surface water temperature and salinity of the surveyed area were 22.08 to $22.87^{\circ} \mathrm{C}$ (mean $22.48^{\circ} \mathrm{C}$ ) and 32.74 to $33.72 \mathrm{psu}$ (mean $33.23 \mathrm{psu}$ ) in October 2020 , and $28.30^{\circ} \mathrm{C}$ and 27.4 psu in July 2021, respectively. The mean water depths for hauls 01,02 , and 03 of the mid-water trawl were 104.2, 107.6, and $110.3 \mathrm{~m}$, respectively (Table 1). During the survey period, a total of 22 species were caught through three mid-water trawls, among which 19 species were identified from 12,625 stereo images obtained using Deep Vision, thus indicating that $86 \%$ of the fish species caught in the trawl were identified by Deep Vision (Table 2). The remaining three species that were not photographed were the Japanese jack mackerel, Pacific rudderfish (Psenopsis anomala), and spearnose grenadier (Caelorinchus multispinulosus) in haul01. In terms of populations, a total of 2102 individuals were collected through trawling, among which a total of 1083 (52\%) were identified using Deep Vision. The deviation of the populations between the two survey methods ranged from $0 \%$ to $2000 \%$, with the largest difference of $2000 \%$ being obtained for chub mackerel and $1748 \%$ 
for skinnycheek lanternfish (Benthosema pterotum) in haul01, whereas Japanese flying squid (Todarodes pacificus), john dory (Zeus faber), Pacific rudderfish, and slender ribbonfish (Trachipterus ishikawae) in haul03 showed no difference in populations. A comparison of the length measurements of 589 individuals caught by mid-water trawl with the lengths of 433 individuals measured using Deep Vision image revealed statistically significant differences with respect to largehead hairtail $(t=-3.04, p=0.0228)$ and glowbelly (Acropoma japonicum $)(t=-2.67, p=0.0111)$ in haul01 and Japanese jack mackerel $(t=4.65, p=0.0000)$ in haul03. There were, however, no significant difference in length measurements obtained for other species (Table 3).

Table 2. Species composition of fish collected using a mid-water trawl in the Western Sea off Jeju Island. $\mathrm{N}$ and $\mathrm{W}$ are number of individuals per unit area (ind. $/ \mathrm{km}^{3}$ ) and wet weight per unit area $\left(\mathrm{kg} / \mathrm{km}^{3}\right)$, respectively.

\begin{tabular}{|c|c|c|c|c|c|c|}
\hline \multirow[b]{2}{*}{ Species } & \multicolumn{2}{|c|}{ Haul01 } & \multicolumn{2}{|c|}{ Haul02 } & \multicolumn{2}{|c|}{ Haul03 } \\
\hline & $\mathbf{N}$ & $\mathbf{W}$ & $\mathbf{N}$ & $\mathbf{W}$ & $\mathbf{N}$ & W \\
\hline Chub mackerel (Scomber japonicus) & 143 & 28.9 & 6 & 1.1 & & \\
\hline Glowbelly (Acropoma japonicum) & 292 & 0.5 & 310 & 0.4 & & \\
\hline Indian perch (Jaydia lineata) & 1233 & 2.2 & & & & \\
\hline Japanese flying squid (Todarodes pacificus) & & & & & 7 & 2.5 \\
\hline Japanese jack mackerel (Trachurus japonicus) & 29 & 2.7 & 24 & 3.4 & 1149 & 253.0 \\
\hline John dory (Zeus faber) & & & & & 4 & 1.5 \\
\hline Largehead hairtail (Trichiurus lepturus) & 1952 & 158.7 & 6 & 0.7 & 186 & 10.6 \\
\hline Pacific rudderfish (Psenopsis anomala) & 29 & 2.7 & 7 & 0.7 & 4 & 0.1 \\
\hline Sharptooth seabass (Synagrops philippinensis) & & & 98 & 0.2 & & \\
\hline Silver pomfret (Pampus argenteus) & 200 & 19.5 & & & & \\
\hline Skinnycheek lanternfish (Benthosema pterotum) & 4239 & 4.0 & & & & \\
\hline Slender ribbonfish (Trachipterus ishikawae) & & & & & 4 & - \\
\hline Spearnose grenadier (Caelorinchus multispinulosus) & 21 & 0.2 & & & & \\
\hline Yellow croaker (Larimichthys polyactis) & 2102 & 39.5 & & & & \\
\hline Total & 10,240 & 258.9 & 451 & 6.5 & 1354 & 267.7 \\
\hline Number of species & & & & & & \\
\hline
\end{tabular}

Table 3. List of species identified and quantified in the Deep Vision images and in the catch data.

\begin{tabular}{|c|c|c|c|c|c|c|c|}
\hline \multirow[b]{2}{*}{ Species } & \multirow[b]{2}{*}{ Haul } & \multicolumn{2}{|c|}{ Counts } & \multirow{2}{*}{ Difference } & \multicolumn{2}{|c|}{ Mean Length (cm) } & \multirow{2}{*}{$p$-Value } \\
\hline & & Images & Catch & & Images & Catch & \\
\hline Chub mackerel (Scomber japonicus) & 1 & $1(1)$ & $21(20)$ & $2000 \%$ & 34.4 & $28.4 \pm 2.0$ & - \\
\hline Chub mackerel (Scomber japonicus) & 2 & $5(5)$ & $3(3)$ & $67 \%$ & $28.3 \pm 2.4$ & $27.8 \pm 1.1$ & 0.7147 \\
\hline Glowbelly (Acropoma japonicum) & 1 & $13(10)$ & $42(30)$ & $223 \%$ & $4.2 \pm 0.9$ & $5.1 \pm 0.9$ & 0.0111 \\
\hline Glowbelly (Acropoma japonicum) & 2 & $227(41)$ & $168(30)$ & $35 \%$ & $4.6 \pm 0.8$ & $4.9 \pm 0.4$ & 0.1656 \\
\hline Indian perch (Jaydia lineata) & 1 & $18(14)$ & $177(30)$ & $883 \%$ & $6.1 \pm 1.0$ & $5.7 \pm 0.5$ & 0.1907 \\
\hline Japanese flying squid (Todarodes pacificus) & 3 & $2(1)$ & $2(2)$ & $0 \%$ & 39.8 & $37.6 \pm 3.0$ & - \\
\hline Japanese jack mackerel (Trachurus japonicus) & 1 & - & $4(4)$ & - & - & $20.4 \pm 4.6$ & - \\
\hline Japanese jack mackerel (Trachurus japonicus) & 2 & $4(3)$ & $13(13)$ & $225 \%$ & $18.1 \pm 10.1$ & $24.1 \pm 1.9$ & 0.4884 \\
\hline Japanese jack mackerel (Trachurus japonicus) & 3 & $423(244)$ & $327(100)$ & $29 \%$ & $25.8 \pm 3.1$ & $27.5 \pm 3.3$ & 0.0000 \\
\hline John dory (Zeus faber) & 3 & $1(1)$ & $1(1)$ & $0 \%$ & 31.6 & 30.3 & - \\
\hline Largehead hairtail (Trichiurus lepturus) & 1 & $123(7)$ & $281(100)$ & $128 \%$ & $34.3 \pm 24.9$ & $63 \pm 9.5$ & 0.0228 \\
\hline Largehead hairtail (Trichiurus lepturus) & 2 & $4(3)$ & $3(3)$ & $33 \%$ & $73.3 \pm 16.9$ & $55.4 \pm 24.8$ & 0.3600 \\
\hline Largehead hairtail (Trichiurus lepturus) & 3 & $93(8)$ & $53(53)$ & $75 \%$ & $43.6 \pm 10.9$ & $50.4 \pm 11.5$ & 0.1265 \\
\hline Pacific rudderfish (Psenopsis anomala) & 1 & - & $4(4)$ & - & - & $18.3 \pm 1.4$ & - \\
\hline Pacific rudderfish (Psenopsis anomala) & 2 & $2(2)$ & $4(4)$ & $100 \%$ & $19.8 \pm 1.56$ & $18.5 \pm 0.9$ & 0.3750 \\
\hline Pacific rudderfish (Psenopsis anomala) & 3 & $1(1)$ & $1(1)$ & $0 \%$ & 8.8 & 9.1 & - \\
\hline Sharptooth seabass (Synagrops philippinensis) & 2 & $37(16)$ & $53(30)$ & $43 \%$ & $5.5 \pm 1.1$ & $5.7 \pm 0.6$ & 0.5314 \\
\hline Silver pomfret (Pampus argenteus) & 1 & $8(5)$ & $29(28)$ & $263 \%$ & $18.3 \pm 3.6$ & $18.3 \pm 1.9$ & 0.9897 \\
\hline Skinnycheek lanternfish (Benthosema pterotum) & 1 & $33(5)$ & $610(30)$ & $1748 \%$ & $4.6 \pm 1.1$ & $5.2 \pm 0.6$ & 0.3047 \\
\hline Slender ribbonfish (Trachipterus ishikawae) & 3 & $1(-)$ & $1(-)$ & $0 \%$ & - & - & - \\
\hline Spearnose grenadier (Caelorinchus multispinulosus) & 1 & - & $3(3)$ & - & - & $15.3 \pm 2.6$ & - \\
\hline Yellow croaker (Larimichthys polyactis) & 1 & $87(66)$ & $302(100)$ & $247 \%$ & $13.1 \pm 1.6$ & $13.5 \pm 1.8$ & 0.0863 \\
\hline
\end{tabular}


Figure 5 shows an echogram for a frequency of $38 \mathrm{kHz}$ and the depth line of the scanmar sensors attached to the top and bottom of the net during haul03 mid-water trawl deployment. The fish schools detected by the scientific echosounder in the research area were irregularly distributed, and towing distance of Scientific Echo Sounder and mid-water trawls and fishing depth were considered for fishing (Figure 5). When fish schools in the same water layer were distributed in various water depths, the fish groups that can be caught at particular water depths were targeted. The average net height of the mid-water trawl when fishing was $26.7 \mathrm{~m}$, and 33 fish schools were detected when towing the midwater trawl. The average height of the detected fish schools within the mid-water trawl range was $2.6 \mathrm{~m}$, which was in the range of 33.7 to $101.8 \mathrm{~m}$ in depth.

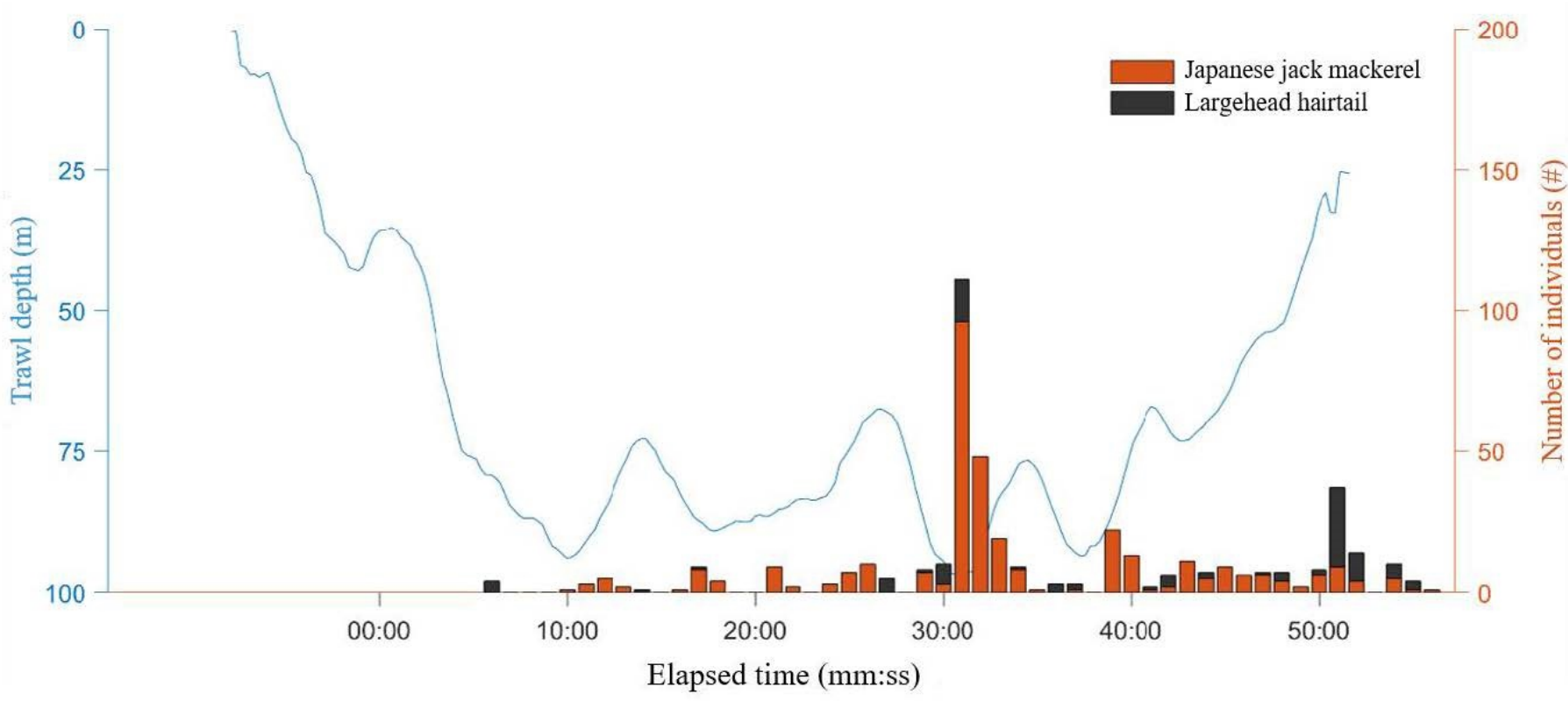

Figure 5. The number of individuals and trawl depth according to elapsed time of largehead hairtail and Japanese jack mackerel caught in mid-water trawl haul03.

In order to identify the spatiotemporal distributions of Japanese jack mackerel and largehead hairtail present in haul03, the population distribution of these species according to water depth was represented graphically using the towing depth data of mid-water trawl and time data from Deep Vision images (Figure 5). A comparison of elapsed trawl time and depth revealed that $41.7 \%$ of the total population of Japanese jack mackerel was photographed at a depth of approximately $100 \mathrm{~m}$ after approximately $30 \mathrm{~min}$ of towing, whereas $38.4 \%$ of the total population of largehead hairtail was observed at the end of the hauling operation at a depth of approximately $30 \mathrm{~m}$.

With regard to the length distribution of yellow croaker (Larimichthys polyactis) in haul01 and Japanese jack mackerel in haul03, which are the major commercial fish species in the surveyed area, we found that the yellow croaker had a greater length distribution at the $13 \mathrm{~cm}$ level, with an average of $13.1 \pm 1.6 \mathrm{~cm}$ for Deep Vision and $13.5 \pm 1.8 \mathrm{~cm}$ for trawls, thereby indicating that the length distribution of the two surveys showed a similar unimodal form. Although we detected no significant differences with respect to Deep Vision $(25.8 \pm 3.1 \mathrm{~cm})$ and trawl $(27.5 \pm 3.4 \mathrm{~cm})$ average values, lengths of the Japanese jack mackerel showed a high bimodal distribution in the $26 \mathrm{~cm}$ and $30 \mathrm{~cm}$ sections, which differed from the unimodal distribution determined using Deep Vision (Figure 6). 

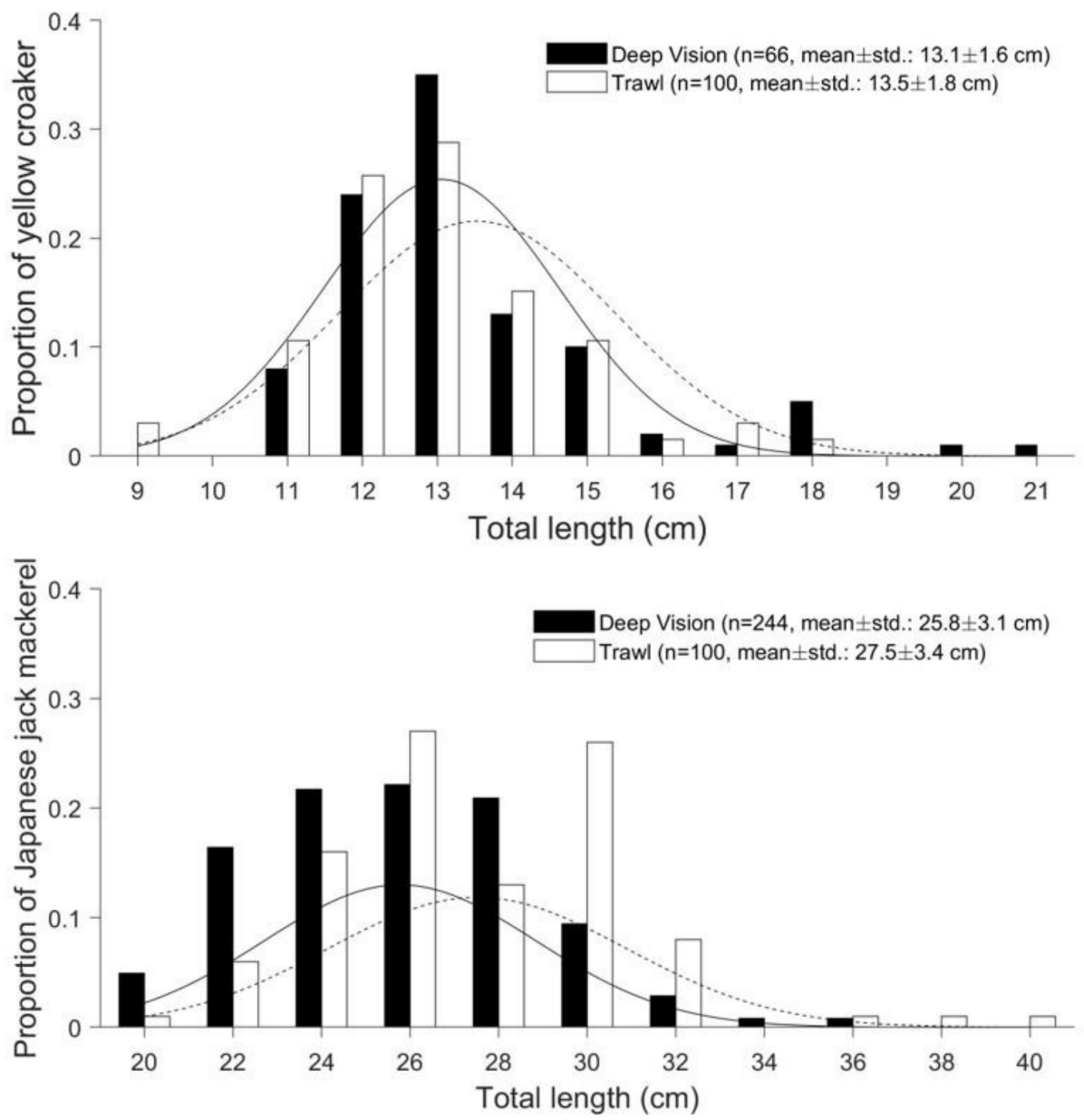

Figure 6. Length comparison of yellow croaker (haul01) and Japanese jack mackerel (haul03) measured using two different methods.

\section{Discussion}

During the investigation period, we collected 22 species over the course of three midwater trawl surveys, among which 19 species from 12,625 images were captured based on analyses of 118,064 Deep Vision stereo images. However, the remaining species, namely Japanese jack mackerel, Pacific rudderfish, and spearnose grenadier, caught during the haul01 trawl were not identified using Deep Vision. This is essentially consistent with the findings of a previous study [17], in which 2 species (silvery pout (Gadiculus argenteus) and Atlantic herring (Clupea harengus)) among 17 species caught in four mid-water trawls were not identified using Deep Vision. In this case, it was established that these two species were obscured from the camera's field of view by a school of blue whiting (Micromesistius poutassou) passing simultaneously through Deep Vision within the trawl. In the present study, we found than more than $50 \%$ of the populations of yellow croaker (87 individuals) and largehead hairtail (123 individuals) captured during haul01 were caught at a specific time, and that at other times, numbers of the three species (Japanese jack mackerel, Pacific rudderfish, and spearnose grenadier) of less than five individuals were obscured from the camera's field of view. However, given that a larger number of individuals were captured from trawls $(n=629)$ and Deep Vision $(n=800)$ during haul02 and haul03, correspondingly higher proportions of individuals were identified from Deep Vision images. For haul01, the number of individuals from trawl catches was approximately $420 \%$ higher than that captured by Deep Vision. Underwood et al. [18] have reported that the number of polar cod (Boreogadus saida) captured using Deep Vision was lower than that obtained by trawling, as these fish passed through Deep Vision during the time in which the net was rising from 
the trawled sea level to the survey vessel. Thus, we suspect that in the case of haul01 in the present study, some individuals moved to the codend whilst Deep Vision was being raised to the survey vessel. Contrastingly, the number of glowbelly recorded during haul02 was higher in Deep Vision (227 individuals) than in the trawl (168 individuals), which we assume to be indicative of the fact that some individuals escaped from the net between the body of the Deep Vision apparatus and the codend, given that the glowbelly is a small species with a total length of $4 \mathrm{~cm}$ or less. This would be consistent with the findings of Rosen and Holst [17], who have reported that the trawl catches of some fish species were underestimated by $47 \%$, owing to a loss of the individuals of species with body lengths of less than $10 \mathrm{~cm}$ during their passage to the codend. With respect to haul03, we found that large numbers of Japanese jack mackerel and largehead hairtail were captured in Deep Vision images compared with those captured by trawling. We believe these differences to be attributable to an error made in calculating the number of Japanese jack mackerel caught by the trawl, due to dividing the entire catch and not obtaining total catch measurements, whereas in the case of the largehead hairtail, numbers were underestimated, as some individuals caught in the net were not sampled while opening the codend and collecting catches.

Differences in the total populations captured and photographed based on fish species analyzed in the three trawl surveys with installed Deep Vision ranged from $0 \%$ to $2000 \%$ (mean 321\%). In contrast to many of the other fish species, chub mackerel showed a significant difference $(2000 \%)$, with one individual being recorded by Deep Vision and 21 from trawls, followed by skinnycheek lanternfish with 33 based on Deep Vision images and 610 from trawls (1748\%). Rosen and Holst [17] have also reported wide variations of between $0 \%$ to $1055 \%$ (mean $106.9 \%$ ) on the basis of four trawl surveys. In the present study, we suspect that the large difference between the numbers of skinnycheek lanternfish recorded using Deep Vision and from trawl catches of haul01 can be attributed to an error in estimating the number of individuals in the total catch by measuring only a few individuals, owing to the large catch size. Consequently, we believe that it would be necessary to increase the number of individuals measured in order to accurately compare the two survey methods.

When comparing fish body lengths measured based on trawl catch and Deep Vision approaches, we found that largehead hairtail and glowbelly captured in haul01 and Japanese jack mackerel captured haul03 showed statistically significant differences (Table 3). In the case of largehead hairtail caught in haul01, it was difficult to precisely compare differences, as the number of samples measured using Deep Vision images (seven individuals) was notably small. In contrast, in the case of Japanese jack mackerel, the number of samples measured (Deep Vision 244 and mid-water trawl 100) was comparatively large, which is considered to be similar to numbers reported by Rosen [15]. These authors found that, based on a comparison of lengths, the two species Atlantic horse mackerel (Trachurus trachurus) and Atlantic mackerel showed a statistically significant difference in Deep Vision image and trawl catch analyses, which was attributable to the particularly small differences in length, owing to the large number of samples and the small length distribution range.

During the present survey, 10 species were collected from haul01 and 6 species from each of hauls 02 and 03. In previous bottom trawl surveys conducted in the seas off Jeju Island [19-21], a variety of fish species were identified differing to those we recorded, which is believed to reflect differences in the additional species of benthic fish caught using bottom trawls. Among these species, Indian perch (Jaydia lineata), yellow croaker, spearnose grenadier, and glowbelly were also captured in the present study. In terms of the number of individuals per unit volume for different hauls, we found that skinnycheek lanternfish in haul01 at 4239 ind. $/ \mathrm{km}^{3}(41.4 \%)$ and glowbelly in haul02 at $310 \mathrm{ind} . / \mathrm{km}^{3}$ $(68.7 \%)$ were the predominant species. Skinnycheek lanternfish are mainly found at depths of around $100 \mathrm{~m}$ or more, although are known to occur at depths of between 80 and $130 \mathrm{~m}$ during the daytime and from 30 to $70 \mathrm{~m}$ at night [22]. In Tosa Bay, Japan, Kaeding et al. [23] have analyzed glowbelly caught by commercial fishing boats at depths of between 100 to 
$300 \mathrm{~m}$. Accordingly, given that the present survey was conducted by trawling at a depth of approximately $100 \mathrm{~m}$ during the daytime, we were, in all probability, sampling from a zone in which skinnycheek lanternfish and glowbelly are more likely to be captured. In haul03, Japanese jack mackerel was the predominantly recorded species with an estimated population of 1149 ind. $/ \mathrm{km}^{3}(94.5 \%)$. In this regard, we believe that the collected mackerel had gathered for spawning, as Japanese jack mackerel inhabit depths of between 10 and $100 \mathrm{~m} \mathrm{[24]} \mathrm{and} \mathrm{the} \mathrm{main} \mathrm{spawning} \mathrm{season} \mathrm{of} \mathrm{these} \mathrm{mackerel} \mathrm{in} \mathrm{the} \mathrm{seas} \mathrm{around} \mathrm{Jeju} \mathrm{extends}$ from March to July [25]. However, given that $50 \%$ of Japanese jack mackerel females are known to have a mature body length of $26.6 \mathrm{~cm}$ [25], it is considered that not all Japanese jack mackerel collected at this time were engaged in spawning.

When analyzing the data, we established that there was a time difference between the acoustic signal of the scientific echosounder and the image captured by the Deep Vision installed on the mid-water trawl, depending on the installation distance, and that there is also likely to have been variations depending on the swimming ability of fish schools. When using only the depth data recorded by Deep Vision, errors may occur in determining the actual distribution depth of fish schools [26]. For example, in the case of the North Atlantic cod (Gadus morhua), it has been reported that these fish moved $360 \mathrm{~m}$ along the trawl at a trawling speed of $1.5 \mathrm{~m} / \mathrm{s}$ for $4 \mathrm{~min}$. It has also been reported that the movement and passage speeds in trawls differ depending on fish species, and that differences may be recorded even for the same fish species, which may have different residence times depending on density or the presence of different fish species in the trawl [26]. Therefore, it is necessary to analyze the location of fish schools by combining the analysis results obtained using Deep Vision and echosounder signals.

Given that the largehead hairtail, one of the major domestic pelagic fish species, has a long non-streamlined body length, entire images of specimens are often not captured, and thus it is difficult to measure lengths accurately. In addition, in the case of small fish, there is a possibility of variation when compared with the catch data, as these fish are often hidden by other fish species or escape through the trawl net prior to taking images.

Finally, we anticipate that, in the future, fishery resource research using Deep Vision will be further refined to facilitate the measurement of small fish species and track overlapping fish species, based on new developments with respect to cameras and analysis software, and will be able to automatically identify fish species via AI and Deep Learning. Therefore, in the future, we believe that this technology will provide an eco-friendly research approach for monitoring pelagic fish resources.

\section{Conclusions}

The Deep Vision stereo camera system collects images of fish passing through trawl extensions. We conducted a survey using Deep Vision in conjunction with a mid-water trawl to identify and measure the lengths of domestic fish species in coastal waters off Jeju Island, Korea, which enabled us to determine the spatiotemporal distribution of a range of different pelagic fish species. However, we found that, when using this system, it is difficult to measure the number of individuals or measure the lengths of target fish species if these are particularly small, large, or long. In addition, some species may swim together to avoid the trawling net, depending on their swimming ability, or may be recorded in Deep Vision at different times or in locations other than their typical range of distribution. Therefore, it is important to interpret spatiotemporal distribution data by taking into consideration factors such as acoustic signals, the depth of field of view, trawl gear, and characteristics of the swimming behavior fish.

Collectively, the results obtained in this study indicate that the combined use of Deep Vision and a mid-water trawl can serve as an eco-friendly and effective approach for examining the spatial distribution of fish species and their sizes without the necessity of catching target species. 
Author Contributions: Original Draft Preparation and Writing: Y.-D.L.; Conceptualization and Review and Editing: H.L.; Analysis of the data: Y.-D.L., E.Y. and C.P.; Software and Validation: E.S.O. and K.L. All authors have read and agreed to the published version of the manuscript.

Funding: This research was funded by National Institute of Fisheries Science (R2022030), Korea.

Informed Consent Statement: Not applicable.

Data Availability Statement: The authors confirm that the data supporting the findings of this study are available within the article.

Conflicts of Interest: The authors declare no conflict of interest.

\section{References}

1. Ole, A.M. Underwater acoustics in marine fisheries and fisheries research. Rev. Fish Biol. Fish. 1997, 7, 1-34.

2. Zhang, C.I. Fisheries Science Series \#1. Marine Fisheries Resources Ecology; Pukyong National University Press: Busan, Korea, 2010; pp. 1-561.

3. Keller, A.A.; Wallace, J.R.; Horness, B.H.; Hamel, O.S.; Stewart, I.J. Variations in eastern North Pacific demersal fish biomass based on the US west coast groundfish bottom trawl survey (2003-2010). Fish. Bull. 2012, 110, 205-222.

4. Koslow, J.A.; Kloser, R.J.; Williams, A. Pelagic biomass and community structure over the mid-continental slope off southeastern Australia based upon acoustic and midwater trawl sampling. Mar. Ecol. Prog. Ser. 1997, 146, 21-35. [CrossRef]

5. Jones, D.T.; Lauffenburger, N.E.; Williams, K.; De Robertis, A. Results of the acoustic trawl survey of walleye pollock (Gadus chalcogrammus) in the Gulf of Alaska, June August 2017 (DY2017-06). AFSC Process. Rep. 2019, 2019, 110.

6. Nøttestad, L.; Utne, K.R.; Óskarsson, G.J.; Jónsson, S.P.; Jacobsen, J.A.; Tangen, Ø.; Anthonypillai, V.; Aanes, S.; Vølstad, J.H.; Bernasconi, M.; et al. Quantifying changes in abundance, biomass, and spatial distribution of Northeast Atlantic mackerel (Scomber scombrus) in the Nordic seas from 2007 to 2014. ICES J. Mar. Sci. 2016, 73, 359-373. [CrossRef]

7. Simmonds, E.J.; MacLennan, D.N. Fisheries Acoustics: Theory and Practice, 2nd ed.; Blackwell Science: Oxford, UK, $2005 ;$ pp. 1-437.

8. Woillez, M.; Ressler, P.H.; Wilson, C.D.; Horne, J.K. Multifrequency species classification of acoustic-trawl survey data using semi-supervised learning with class discovery. J. Acoust. Soc. Am. 2012, 131, EL184-EL190. [CrossRef] [PubMed]

9. Kracker, L.M. The geography of fish: The use of remote sensing and spatial analysis tools in fisheries research. Prof. Geogr. 1999, 51, 440-450. [CrossRef]

10. Jones, J.B. Environmental impact of trawling on the seabed: A review. N. Z. J. Mar. Freshw. Res. 1992, 26, 59-67. [CrossRef]

11. Brodeur, R.D. Habitat-specific distribution of Pacific ocean perch (Sebastes alutus) in Pribilof Canyon, Bering Sea. Cont. Shelf Res. 2001, 21, 207-224. [CrossRef]

12. Honda, N.; Watanabe, T. Vertical distribution survey of the giant jellyfish Nemopilema nomurai by an underwater video camera attached to a midwater trawl net. Nippon Suisan Gakkaishi 2007, 73, 1042-1048. [CrossRef]

13. Logan, J.M.; Young, M.A.; Harvey, E.S.; Schimel, A.C.; Ierodiaconou, D. Combining underwater video methods improves effectiveness of demersal fish assemblage surveys across habitats. Mar. Ecol. Prog. Ser. 2017, 582, 181-200. [CrossRef]

14. Seiler, J.; Williams, A.; Barrett, N. Assessing size, abundance and habitat preferences of the Ocean Perch Helicolenus percoides using a AUV-borne stereo camera system. Fish. Res. 2012, 129, 64-72. [CrossRef]

15. Rosen, S.; Jörgensen, T.; Hammersland-White, D.; Holst, J.C. Deep Vision: A stereo camera system provides highly accurate counts and lengths of fish passing inside a trawl. Can. J. Fish. Aquat. Sci. 2013, 70, 1456-1467. [CrossRef]

16. Allken, V.; Rosen, S.; Handegard, N.O.; Malde, K. A real-world dataset and data simulation algorithm for automated fish species identification. Geosci. Data J. 2021, 8, 199-209. [CrossRef]

17. Rosen, S.; Holst, J.C. Deep Vision in-trawl imaging: Sampling the water column in four dimensions. Fish. Res. 2013, 148, 64-73. [CrossRef]

18. Underwood, M.J.; Rosen, S.; Engås, A.; Eriksen, E. Deep vision: An in-trawl stereo camera makes a step forward in monitoring the pelagic community. PLoS ONE 2014, 9, e112304. [CrossRef]

19. Jeong, S.B.; Hwang, D.J.; Kim, Y.J.; Shin, H.H.; Son, Y.U. Species composition of the catches collected by a bottom trawl in the Southern Waters of Korea in summer, 2004. Bull. Korean Soc. Fish. Technol. 2005, 41, 35-45.

20. Park, Y.; Yoo, J.; Shin, H.H.; Kim, Y.; Kim, D. A Study on fishes caught by trawl survey in West coastal sea area of Je-ju Island. Bull. Fish. Sci. Inst. Chonnam Natl. Univ. 2021, 14, 50-55.

21. Shin, H.H.; Hwang, D.J.; Kim, Y.J. Studies on the distribution of fisheries resources by bottom trawling in the Yellow Sea. Bull. Korean Soc. Fish. Technol. 2002, 38, 129-139.

22. Valinassab, T.; Pierce, G.J.; Johannesson, K. Lantern fish (Benthosema pterotum) resources as a target for commercial exploitation in the Oman Sea. J. Appl. Ichthyol. 2007, 23, 573-577. [CrossRef]

23. Kaeding, A.J.; Ast, J.C.; Pearce, M.M.; Urbanczyk, H.; Kimura, S.; Endo, H.; Nakamura, M.; Dunlap, P.V. Phylogenetic diversity and cosymbiosis in the bioluminescent symbioses of "Photobacterium mandapamensis". Appl. Environ. Microbiol. 2007, 73, 3173-3182. [CrossRef] [PubMed]

24. Kim, I.S.; Choi, Y.; Lee, C.L.; Lee, Y.J.; Kim, B.J.; Lim, J.H. Illustrated Book of Korean Fish; Kyo-Hak Publ.: Seoul, Korea, 2005; 615p. 
25. Cha, H.K.; Lee, J.B.; Kang, S.; Chang, D.S.; Choi, J.H. Reproduction of the jack mackerel, Trachurus japonicus Temminck et Schlegel in the coastal waters around Jeju Island, Korea: Maturation and spawning. J. Korean Soc. Fish. Technol. 2009, 45, 243-250. [CrossRef]

26. Underwood, M.J.; Rosen, S.; Engås, A.; Jørgensen, T.; Fernö, A. Species-specific residence times in the aft part of a pelagic survey trawl: Implications for inference of pre-capture spatial distribution using the Deep Vision system. ICES J. Mar. Sci. 2018, 75, 1393-1404. [CrossRef] 